NBER WORKING PAPER SERIES

\title{
GLOBAL CORPORATIONS AND LOCAL POLITICS: A THEORY OF VOTER BACKLASH
}

\author{
Eckhard Janeba \\ Working Paper 8254 \\ http://www.nber.org/papers/w8254 \\ NATIONAL BUREAU OF ECONOMIC RESEARCH \\ 1050 Massachusetts Avenue \\ Cambridge, MA 02138 \\ April 2001
}

I am grateful to John Cadigan, Ron Davies, Murat Iyigun, Jim Markusen and Jay Wilson for helpful comments. Thanks also to seminar and conference participants at Oregon, Colorado, the Midwest International Meetings in Minnesota (Fall 2000) and the NBER ITI group's Fall 2000 meeting in Palo Alto. The views expressed herein are those of the author and not necessarily those of the National Bureau of Economic Research.

(C) 2001 by Eckhard Janeba. All rights reserved. Short sections of text, not to exceed two paragraphs, may be quoted without explicit permission provided that full credit, including $(\mathcal{C}$ notice, is given to the source. 
Global Corporations and Local Politics: A Theory of Voter Backlash

Eckhard Janeba

NBER Working Paper No. 8254

April 2001

JEL No. D78, F23, H2

\begin{abstract}
Host governments often display two types of behavior toward outside investors. At an initial stage they eagerly compete for production facilities by offering subsidy packages, but often reverse these policies at a later point. In contrast to the literature that explains the behavior as a result of a hold-up problem, this paper argues that policy reversals are the result of a change in the policy choice or identity of the policy maker. Voters disagree over the net benefits of attracting corporations because of a redistributional conflict. Economic shocks change who is policy maker over time by affecting (i) the number of people who support the corporation, (ii) the incentive of an opponent of the firm to become a candidate, and (iii) the opponent's probability of winning the election against a proponent. The paper shows also that societies with more skewed income distributions are less likely to attract outside investment. While the interpretation of the model is cast in the context of foreign investment, the model has more applications and can be seen as a general theory of voter backlash.
\end{abstract}

Eckhard Janeba University of Colorado at Boulder Department of Economics

Campus Box 256

Boulder, CO 80309-0256

and NBER

Tel: (303) 492-5923

Email: eckhard.janeba@colorado.edu 


\section{Introduction}

Globalization is an important cause for the increase in economic well being by improving the worldwide allocation of resources and by fostering international competition. Yet globalization is also reason for concern about the viability of the nation state because increased openness limits the ability to redistribute resources among citizens, it may contribute to larger income inequality, and openness potentially exposes people to higher volatile incomes. ${ }^{1}$ This tension becomes quite clear when governments compete for foreign investment by offering tax breaks or outright subsidies to global corporations in order to increase local employment, boost domestic wages and generate technological spillovers. The financing of these location incentives typically requires less spending on other government services or a shift of tax burden to immobile factors. Thus, there is a potential conflict of interest between citizens who differ in preferences for government services or sources of income.

The present paper models the political conflict and develops a theory of voter backlash when a region needs to offer a subsidy to attract a global corporation that generates additional income in the host region. A backlash is said to occur if the region is initially willing to pay a subsidy to the corporation, but stops paying the subsidy in a later period and therefore the corporation exits. The perhaps surprising feature of the model is that the policy reversal can occur even if the corporation generates the same gross benefit for all citizens and the benefit is larger than the per capita subsidy necessary to attract or keep the corporation. To understand this result it is useful to explain first the nature of the political conflict in any given period. There is disagreement over the value of the presence of the corporation because the after-tax benefit of the corporation's presence is tied to an individual's preference for redistributive taxation. When the benefit of the corporation is the same for all individuals, it is the "middle class" who supports the presence of the firm because a middle-class person prefers zero or small tax rates for redistributional purposes and hence makes the after-tax benefit from the coporation identical (or very similar) to the gross benefit. Individuals who favor a strongly progressive or regressive income tax in the absence of the corporation, find that attracting the corporation is too costly in terms of forgone redistribution.

Yet the outcome of the political conflict may change over time. The policy choice and

the identity of the elected policy maker is affected by economic disturbances because a shock

\footnotetext{
${ }^{1}$ See Rodrik (1997) for an analysis of these aspects of globalization.
} 
to the host region leaves the firm's outside option unaffected. The shock in turn changes how individuals evaluate the trade-off between the net benefits of having the corporation present and the forgone redistribution. The economic shock may originate inside or outside the host region. For example, the decline of an existing industry due to a world price shock decreases individual earnings and affects the political outcome. An important contribution of the paper is to show that the exact effects of a shock depend on (i) the distribution of gross benefits from the corporation's presence and (ii) which host region variables are affected by the shock.

In particular, I show that a negative shock to all host variables reduces the number of supporters of the corporation (if they were elected policymaker), increases both an opponent's incentive to become a candidate (holding the winning probability constant) and the opponent's probability of winning the election against a proponent (holding the set of candidates fixed). Yet the first of these results is reversed if the shock affects all host variables except the benefit from the corporation. The robustness of these and other results are checked by considering also the case in which the distribution of gross benefits from the corporation are proportional to the exogenously given individual income rather than independent of individual earnings.

The voter backlash hypothesis offers a novel explanation for the reversal of host government decisions. Host governments frequently display two types of behavior toward outside investors. Initially they eagerly compete for the firm by offering subsidies or tax breaks and then, after the firm has made its location choice, reverse their policy decision. This often leads to the exit of the corporation from the host region. The traditional explanation for the phenomenon is that after the firm is locked in, the bargaining power shifts from the firm to the host government. ${ }^{2}$ This argument is well understood and empirically relevant, but it is also in an important sense incomplete because there are other reasons for policy reversals. I will discuss anecdotal evidence for the voter backlash hypothesis and related empirical studies in section 6 .

The main result of the paper can be interpreted in a different way. Instead of looking at the political outcome in one particular host region over time, the model predicts that

\footnotetext{
${ }^{2}$ See, for example, Bond and Samuelson (1989) and Doyle and van Wijnbergen (1994), who discuss firm investment strategies and optimal taxes.
} 
in a cross-sectional analysis countries with less skewed distributions of earnings are more likely to attract foreign investment. The result holds if income inequality is measured by the gap between mean and median income, and if the median voter is always elected policy maker. When mean and median income are closely aligned, the median income person favors little or no redistributive taxation in the absence of the corporation and thus also favors the presence of the corporation as long as the gross benefit of the corporation exceeds the subsidy payment. Yet even if median income equals mean income, the firm may be rejected. I show that under some conditions an equilibrium exists in which two opponents of the firm run for office and win with probability one half.

While the interpretation of the model is cast in the context of foreign investment by multinational firms, it should be pointed out that the theory of voter backlash developed in this paper has more general appeal and potential for wider applications. For example, citizens in a closed economy may consider adopting a project that generates additional income for all citizens (not necessarily the same). If the costs of the project are unaffected by random events - or not affected in the same way as the benefits of the project and other variables - a voter backlash can occur. In the following I use the foreign investment interpretation because policy reversals are quite common in this context.

The modeling of the political process is based on the citizen-candidate model that was developed by Osborne and Slivinski (1996) and Besley and Coate (1997). In a citizencandidate model each citizen can become a candidate for office and the winner of the election implements her most preferred policy. Running for office entails paying a cost, e.g., costs for campaigning, which prevents all citizens from becoming candidates. The advantage of this framework for the present purpose is twofold. It allows me to pin down the identity of the policy maker and hence the idea of a voter backlash can be captured in a meaningful sense. Secondly, the citizen-candidate model can handle the multi-dimensional policy space easily because ctizens vote for candidates and not directly for policies.

The present paper shares similarities and a common interest in understanding policy choice with Besley and Coate (1998). Yet the two papers also differ and complement each other. Besley and Coate analyze in a closed-economy the efficiency effects of political decision making in a dynamic context. The elected policy maker in period 1 decides whether the government undertakes a costly investment that generates benefits for some citizens in the 
next period. The investment may not be undertaken if today's policy maker cannot ensure that potential losers are compensated in the future or if it harms the present policy maker in the future because the identity of the policy maker changes as a result of the investment. By contrast, the present paper assumes that costs and benefits of the project occur simultaneously and repeatedly, and the gross benefits are shared equally by all citizens. There is nevertheless political conflict because the evaluation of the project is tied to the preference for redistribution.

The idea in this paper complements and is in contrast to Coate and Morris (1999) who develop a theory of policy persistence. They correctly observe that inefficient policies are often maintained over time, like support for farmers who have become wealthy, or protection for import-competing industries long after the strategy is considered useful. Coate and Morris show within a lobbying framework following Grossman and Helpman (1994) that the implementation of a policy in the current period increases the likelihood of continuation of that policy in the future. By contrast, this paper argues that there are policy areas, like the tax treatment of inward foreign direct investment, where policy reversals frequently occur. Yet even in the present framework policy is likely to be persistent if the underlying economic conditions do not change.

The idea of a political backlash is discussed in Laban and Wolf (1993). In the context of large-scale privatization in transition economies, they point out that the private return of buying a privatized firm depends on the likelihood of the continuation of a market-friendly policy, which in turn depends on the aggregate amount of privatization. There is the possibility of a political backlash if the aggregate amount of privatization does not reach a critical mass effect. A related point is made by Rodrik (1991) who argues that the likelihood of a policy reform being sustainable depends on the response of private investment to the reform.

The paper is organized as follows: The next section introduces the model. Section 3 contains the main results under a uniform structure of benefits from the corporation. The case of proportional benefits is analyzed in section 4. Section 5 illustrates the working of the model by way of examples. Section 6 considers anecdotal evidence and discusses the results of the paper in the context of empirical studies on the factors explaining foreign direct investment. Section 7 concludes and discusses possible extensions. 


\section{The Model}

\section{Overview}

I begin with an overview of the main features of the model which are then described in more detail below. Consider a region whose individuals live for two periods. Individuals differ in terms of income and therefore there is political conflict over public policy. In each period individuals must elect a person who decides on a proportional income tax rate, a uniform lump sum subsidy, and whether a corporation is attracted or kept. In the base version of the model I assume that the firm can be attracted in period 2 even when it was not present in the region in period 1. If present in any period, the corporation generates additional income for all individuals. For the firm to be attracted in any period, the government needs to pay a subsidy to the firm that must be financed through distortionary taxation.

The two periods differ in one important respect. At the beginning of period 2 the region experiences a region-specific, proportional shock. The key objective of the analysis is to characterize conditions under which the firm is attracted in period 1, but voters decide in period 2 not to pay the subsidy necessary to keep the firm in the region. If this happens, the region reverses its earlier decision and I call this a voter backlash. The focus of the model is on the region's internal decision making and not on the corporation. The firm always gets the value of its outside option regardless of whether the firm produces in the region or not.

\section{Model Description}

I now turn to the detailed description of the model. The region is inhabited by a finite number of individuals $N$, indexed by superscript $i=1, \ldots, N$, who in each period $t$ (subscript $t=1,2)$ derive utility from net income $w_{t}^{i}$. For simplicity I assume that $N$ is odd. Preferences are assumed to be identical for all individuals. Let the utility of individual $i$ be

$$
u\left(w_{1}^{i}, w_{2}^{i}\right)=f\left(w_{1}^{i}\right)+h\left(w_{2}^{i}\right)
$$

where the functions $f$ and $h$ are increasing. Net income in period $t, w_{t}$, consists of four sources (I omit index $i$ if no confusion is possible). First, there is a person-specific and exogenously given income component $y_{t}$, called private income. Differences in private income may be the result of differences in skills or differences in the mix of labor and capital income. Denote the lowest and highest income $\underline{y}_{t}$ and $\bar{y}_{t}$. Average private income in period $t$ is $Y_{t}=N^{-1} \sum_{i} y_{t}^{i}$. 
The second source of income is obtained if the region attracts the global corporation. In that case citizen $i$ receives $m_{t}^{i} \geq 0$. Call this extra income. I consider two cases. In the first case extra income is uniform across all individuals in any given period, i.e. $m_{t}^{i}=m_{t}$ for all $i$. In the second case extra income is assumed to be proportional to private income, $m_{t}^{i}=k y_{t}^{i}$, for $k>0$. The choice of these two cases is partly driven by analytical aspects. Both cases are fairly easy to solve and allow me to check the robustness of results. Extra income may stand for a variety of benefits that are directly or indirectly generated by the corporation: an increase in the region's wage rate as a result of an increase in labor demand, a reduction in unemployment in the presence of a fixed wage, technological spillovers to other business, agglomeration benefits, etc. Note that if $m_{t}$ is uniform, $m_{t} / y_{t}$ is falling in private income. Thus the benefits of the corporation are concentrated at the lower end of the income distribution. This seems to be a reasonable feature, in particular when multinationals set up assembly plants that tend be intensive in low- to medium-skilled workers. The uniformity assumption does not imply, however, that low-income individuals always prefer attracting the firm, as will be shown later.

Third, in each period the government makes a uniform lump sum payment $g_{t}$ to all individuals. Revenues for this payment come from taxing private and extra incomes. I allow for the possibility that the transfer is a tax, i.e., $g_{t}<0$.

Finally, if an individual becomes a candidate for office, she must pay the cost of candidacy $c_{t} \geq 0$ which may reflect campaign cost or the cost associated with being in the public eye. If the person is not a candidate, this component is zero.

Since the region may decide not to attract the corporation, we can write individual income in period $t$ as

$$
w_{t}^{i}=\left(1-\tau_{t}\right)\left(y_{t}^{i}+\delta_{t} m_{t}^{i}\right)+g_{t}-\varepsilon_{t}^{i} c_{t}
$$

where $\delta_{t}$ and $\varepsilon_{t}$ are indicator variables. The variable $\delta_{t}$ takes the value of one when the firm is present in period $t$, and $\delta_{t}=0$ if not. If an individual is a candidate in period $t$, then $\varepsilon_{t}=1$ and zero otherwise. The proportional income tax rate in period $t$ is $\tau_{t}$. Note that extra income is considered taxable income.

To attract or keep the corporation, the government of the region must pay a subsidy $S$ to the corporation in that period (but the same in all periods). The government raises revenues 
through a proportional income tax $\tau_{t}$ which is levied on $y_{t}$ and $m_{t}$ (if the corporation is present in that period) to pay for the subsidy to the corporation and the lump sum payment $g_{t}$ to all individuals. I assume, however, that there is a government inefficiency, similar to Perotti (1993). Each tax dollar raised allows spending of only $1-\tau$ dollars. $^{3}$ This gives rise to a quadratic revenue function in $\tau$ and makes the model tractable. The government budget constraint in per capita terms for period $t$ is then

$$
\tau_{t}\left(1-\tau_{t}\right)\left(Y_{t}+\delta_{t} \bar{m}_{t}\right)=g_{t}+\delta_{t} s
$$

where $s=S N^{-1}$ is the per capita subsidy to the corporation and $\bar{m}_{t}=N^{-1} \sum_{i} m_{t}^{i}$ is average extra income. In the uniform case $m_{t}=m_{t}^{i}=\bar{m}_{t}$ for all $i$. I allow for the possibility that $\tau$ is negative and hence the uniform lump sum subsidy $g$ becomes a lump sum tax. This case is still consistent with the loss function that describes the government inefficiency. For every dollar raised in revenues through $g$, the government can subsidize private income only at the rate $1 / \tau(1-\tau)<0$ which is less in absolute value than the rate $1 / \tau$ under no government inefficiency.

The situation in the two periods is the same except for a region-specific shock at the beginning of period 2 that leaves the firm's outside option unaffected. An example may illustrate: The region experiences unemployment due to an above-equilibrium fixed wage. Suppose there is a shock to the region's other industries or a shock to labor supply. The global corporation is unaffected by the shock if, as is assumed, the shock has no impact on the fixed wage and the productivity of the corporation. Thus the region has to continue to pay $S$ to the corporation. ${ }^{4}$ The shock affects private incomes and the cost of candidacy, but may or may not affect extra incomes. I consider both possibilities to show that results depend on the particular shock structure.

Suppose $\lambda \in(0, \infty)$ is a random variable. Private incomes in period 1 and 2 are then related as follows. Each individual's period 2 private income is proportional to period 1's income,

$$
y_{2}^{i}=\lambda y_{1}^{i}
$$

\footnotetext{
${ }^{3}$ Alternatively, allowing for variable labor supply would endogenize private (labor) income and introduce a tax distortion with similar effects.

${ }^{4} \mathrm{I}$ abstract from the improved bargaining power of the corporation as a result of the increased value of the corporation for the region as a whole.
} 
Thus $Y_{2}=\lambda Y_{1}, \underline{y}_{2}=\lambda \underline{y}_{1}$ and $\bar{y}_{2}=\lambda \bar{y}_{1}$. In situation 1 , the shock affects also extra income

$$
m_{2}^{i}=\lambda m_{1}^{i}
$$

In this case equations (4) and (5) imply that the ratio of extra income and private income is the same in both periods. Situation 1 can be interpreted in the unemployment context: If a region experiences a sudden inflow of workers, more workers are seeking employment with the global corporation and with other employers. This lowers in expected terms private incomes and the benefit per worker from the corporation.

Alternatively, the shock leaves extra incomes unaffected (situation 2)

$$
m_{2}^{i}=m_{1}^{i}
$$

Finally, I assume that $c_{t}$ is affected by the shock as well, i.e.,

$$
c_{2}=\lambda c_{1}
$$

This assumption is made to show how in situation 1 a shock that proportionally affects all host region variables changes the political equilibrium. The case $c_{2}=c_{1}$ will be considered as well, though without much affecting results.

The decisionmaking in this model follows the citizen-candidate literature: In each period, individuals must elect someone who chooses the tax rate $\tau$, the lump sum payment $g$, and who decides whether the firm is attracted (or kept) or not, i.e., chooses $\delta=1$ or $\delta=0$. Citizens vote for one person from the set of self-declared candidates. The person with the highest number of votes wins (plurality rule). In case of ties, each tying person wins with equal probability. In their voting decision, each citizen maximizes her expected utility (where the randomness comes from the possibilities of ties in an election). If elected, an individual can implement his or her most preferred policy in that period. In each period each individual must decide whether to become a candidate or not. In doing so, she takes the entry decisions of all other individuals as given and correctly anticipates the voting decision of all citizens and the preferred policy implemented by the winner. The set of entry decisions must form a Nash equilibrium (possibly in mixed strategies). If no individual becomes a candidate in period $t$, I assume that the default policy is $\tau_{t}=g_{t}=\delta_{t}=0$. 
Solving for the equilibrium of the two period economy is simplified because the firm can be attracted in period 2 even if absent in period 1. In this case the two periods can be analyzed separately. The decision in period 1 does not change the set of feasible policies or the political process in period 2. There are no irreversibilities in the firm's investment decision and there is no incumbent advantage in period 2 for the individual who was elected in period 1. I will return to these assumptions in the concluding section.

The second observation is that in each period an equilibrium for the political game exists despite the multidimensional policy space. The reason for this is that the political contest is a finite game. A finite number of players choose from a finite set of alternatives (become a candidate or not). Hence, Nash's Theorem can be applied.

Before we proceed, it is useful to recall the various scenarios. Extra income may be proportional to or independent of private income. The shock at the beginning of period 2 may or may not affect extra income. This gives four possible scenarios. I consider first the case of uniform extra income under the two shock structures. In section 4 the proportional case is analyzed.

\section{Extra Income is Uniform}

I solve the model in three steps. First, I characterize the most preferred policy of an individual with private income $y_{t}$. This allows me to explain why there is political conflict over the presence of the firm even if extra income is the same for all individuals. In a second step I identify an equilibrium of the political game in period $t$ with one or two candidates. In the last step I demonstrate the possibility of a voter backlash by showing how the number of supporters of the firm, the incentive to becoming a candidate, and the probability of winning change when shocks occur at the beginning of period 2 .

\section{The Most Preferred Policy}

As a first step to solving the model I characterize each individual's most preferred policy in period $t$ if the individual was elected policy maker. An individual maximizes $w_{t}$ by choosing $\tau_{t}, g_{t}$ and $\delta_{t}$. The problem is complicated by the fact that $\delta$ is a zero-one variable and that all individuals must have nonnegative income in each period, i.e. $w_{t}^{i} \geq 0$ for all $i$. When extra income is uniform, it is useful to define two threshold levels of private income 
when $m_{t} \geq s$ :

$$
\begin{aligned}
y_{t}^{*} & =Y_{t}-2 \sqrt{Y_{t}\left(Y_{t}+m_{t}\right)\left(1-s m_{t}^{-1}\right)} \\
y_{t}^{* *} & =Y_{t}+2 \sqrt{Y_{t}\left(Y_{t}+m_{t}\right)\left(1-s m_{t}^{-1}\right)} .
\end{aligned}
$$

Note that $y_{t}^{*} \leq Y_{t} \leq y_{t}^{* *}$ and the three values coincide if $m_{t}=s$. This leads to

Proposition 1 Assume extra income is uniform $\left(m_{t}=m_{t}^{i}=\bar{m}_{t}\right.$ for all $\left.i\right)$ and $\bar{y}_{t} \leq 2 \underline{y}_{t}+Y_{t}$. In period $t$, the most preferred policy by an individual with income $y_{t}$ is

a) $\left\{\delta_{t}=1, \quad \tau_{t}=\frac{Y_{t}-\vartheta_{t}}{2\left(Y_{t}+m_{t}\right)}, \quad g_{t}=\frac{\left(Y_{t}-y_{t}\right)\left(Y_{t}+y_{t}+2 m_{t}\right)}{4\left(Y_{t}+m_{t}\right)}-s\right\}$ if $y_{t} \in\left[y_{t}^{*}, y_{t}^{* *}\right]$ and $m_{t} \geq s$. Hence the individual prefers paying the subsidy to the corporation.

b) $\left\{\delta_{t}=0, \quad \tau_{t}=\frac{Y_{t}-y_{t}}{2 Y_{t}}, g_{t}=\frac{Y_{t}^{2}-y_{t}^{2}}{4 Y_{t}}\right\}$ otherwise. Thus the individual rejects the corporation.

Proof: See Appendix

Remark 1: The assumptions $\bar{y}_{t} \leq 2 \underline{y}_{t}+Y_{t}$ ensures that the most preferred policies can be easily characterized because the constraint $w_{t}^{i} \geq 0$ is never binding. In this sense the assumption is made for convenience. In an example in a later section I will consider a situation in which the assumption is violated and the need to determine the most preferred policy when the constraint is binding arises.

Proposition 1 may seem surprising at first glance. Why is anybody against the corporation even when $m_{t}>s$, in particular when the person has above average income? To answer this question it is useful to recall the standard result known from Meltzer and Richard (1981) for a closed economy. Individuals' most preferred tax rates are ordered inversely by income. The higher is personal income, the lower is the most preferred tax rate. Individuals with below average income choose a positive tax rate and a lump sum transfer in order to implement a progressive tax system (measured by the change in the average tax rate $(\tau y-g) / y$ ). By contrast, rich individuals with above average income choose a labor subsidy that is financed by a lump sum tax, thereby making the tax system regressive. ${ }^{5}$ Average income individuals choose zero taxes and transfers.

\footnotetext{
${ }^{5}$ This assumes that the poorest person has strictly positive income. Otherwise the tax rate and the lump sum transfer are constrained to be nonnegative. Meltzer and Richard make that assumption.
} 
Consider now the possibility of attracting the corporation. For some given tax rate $\tau$, an individual's income changes as follows: The first effect is an increase in net income by $(1-\tau) m$. In addition, the government lump sum subsidy $g$ changes by $\tau(1-\tau) m-s$. Hence the change of net income at a given tax rate is the combined effect and equals $\left(1-\tau^{2}\right) m-s$. Assuming $m>s$, the term is positive when the tax rate is sufficiently close to zero, but negative otherwise. In other words, the optimal tax rate that maximizes the net benefit from the corporation is zero.

Relatively poor and relatively rich individuals therefore face a tradeoff between the two objectives, redistribution of income and maximizing the net benefit of the corporation's presences. This explains why individuals whose incomes are far apart from the average income (i.e., outside the interval $\left[y_{1}^{*}, y_{1}^{* *}\right]$ ) are against the corporation because their most preferred tax rate for redistributional purposes is large in absolute terms. In particular, a very rich individual likes to subsidize labor income in the absence of the firm.

Proposition is illustrated in Figure 1, which plots the preferred tax rate, lump sum payment and the $\delta$-variable as a function of private income.

In the remainder of the paper, I will assume that $m_{1}>s$ and the set $\left[y_{1}^{*}, y_{1}^{* *}\right]$ is a strict subset of the set $\left[\underline{y}_{1}, \bar{y}_{1}\right]$ so that some but not all people favor the corporation in period 1 .

\section{A Characterization of the Political Equilibrium in Period $t$}

Which individual will be elected to implement her most preferred policy? The following result establishes a simple condition under which the person with median income $y^{m}$ becomes the elected policymaker. Under additional assumptions, I also demonstrate the existence of an equilibrium with two candidates who enter and win with probability one half. Further equilibria may exist. The purpose is not to provide a full characterization of all equilibria, but rather to show the properties of some intuitive and simple equilibria.

Proposition 2 Assume the cost of running for office are sufficiently small.

a) The following is an equilibrium of the political game in period t: The person with median income runs uncontested and becomes elected policymaker. In this equilibrium, the firm is not attracted (or kept) if the distribution of private incomes is too skewed, 
i.e., for given average private income $Y_{t} \in\left[y_{t}^{*}, y_{t}^{* *}\right]$ the median income lies either below $y_{t}^{*}$ or above $y_{t}^{* *}$.

b) Suppose the distribution of private incomes is single-peaked, symmetric around average income, less than one third of the population has private income between $y_{t}^{*}$ and $y_{t}^{* *}$, and the two threshold levels satisfy $\underline{y}_{t}<y_{t}^{*}<y_{t}^{* *}<\bar{y}_{t}$. Then there exists an equilibrium with two candidates whose incomes are $y_{t}^{1}=y_{t}^{*}-\alpha$ and $y_{t}^{2}=y_{t}^{* *}+\alpha$, where $\alpha$ is a small positive number. In this equilibrium the firm is rejected.

Proof: a) Consider first the condition of entry for the median income person. If the person does not enter, the default policy is $\tau_{t}=g_{t}=\delta_{t}=0$ and the person's utility is $y_{t}^{m}$. If elected, the person with median income has utility $\left(Y_{t}+y_{t}^{m}\right)^{2} / 4 Y_{t}-c_{t}$ when the person's optimal policy is $\delta_{t}=0$. The median person enters if $c_{t}=0$ and by continuity enters also if $c_{t}$ is positive but sufficiently small. The same type of argument applies when the median person prefers $\delta_{t}=1$. This guarantees entry of the median income person.

Consider next entry of another candidate who runs against the median income person. Nobody with the same income as the median income person enters because policy is unaffected but running for office is costly. Suppose then somebody with income $\widehat{y} \neq y_{t}^{m}$ enters. This person would surely lose the election. To see this, find the person who is indifferent between the two candidates. That person's private income $\widetilde{y}$ must lie between the two candidates' incomes for the following reason. A person with income sufficiently close to the entrant prefers strictly the entrant, while a person with income sufficiently close to the median income prefers the median income individual. By continuity then, there must exist an income level in between such that this person would be indifferent. Note also that all individuals with incomes $y<\widetilde{y}$ prefer the entrant (median income person) if $\widehat{y}<y^{m}\left(\widehat{y}>y^{m}\right)$, while all individuals with incomes $y>\widetilde{y}$ prefer the median income person (entrant) if $\widehat{y}>y^{m}$ $\left(\widehat{y}<y^{m}\right)$. Hence, the median income person gets more than half of the votes. The second part of statement a) follows now immediately from Proposition 1.

Statement b) holds because the symmetry of the candidates' position around average income and the properties of the distribution of private incomes implies that each candidate receives half of the votes and hence wins with probability one half. Entry is optimal for each candidate if the cost of running are zero (or by continuity sufficiently small). No other 
citizen has an incentive to enter because she would surely lose. In particular no person with income between the candidates enters because she could get no more than one third of the vote which is less than the two other candidates get. The firm is rejected since the two candidates' incomes are outside the supporting interval. Q.E.D.

The intuition for the first part of Proposition 2 is straightforward. The support for the corporation, as described in Proposition 1, depends only on average income, extra income and the subsidy paid, but not on median income. Thus the median income person, if elected, may not want to attract or keep the firm if the person's income is much lower (or higher) than average income. This result has an interesting corollary if economies with identical average income but different median income are compared. Consider a global corporation that can invest in either of two economies that have the same average private income $Y$, but differ in their median incomes $y^{m_{i}}$ such that either $y^{m_{1}}<y^{*}<y^{m_{2}}<y^{* *}$ or $y^{*}<y^{m_{2}}<y^{* *}<y^{m_{1}}$. The following corollary is then straightforward.

Corollary Economies with less skewed income distributions are more likely to attract outside investment if the median income person is always elected policy maker.

Proposition 2a and the Corollary suggest that too much skewness in the distribution of private incomes is detrimental to attracting the firm or foreign investment in general. Proposition $2 \mathrm{~b}$, however, shows that a large skewness in the distribution of private incomes is not necessary for a rejection of the firm. Even when average and median income are perfectly lined up, as in Proposition 2b, the elected policy maker may not want to attract the firm. This happens if two opponents of the firm, but with different redistributional objectives, enter the political race and win with probability one half.

\section{The Voter Backlash}

I now turn to the effects of shocks on the political outcome in period 2. Formally, I analyze how the critical income values $\left(y_{t}^{*}, y_{t}^{* *}\right)$ or the income value of a particular voter changes continuously with the shock variable $\lambda$. Of course, the shock may have no effect at all because I assumed that the number of individuals is finite and hence a small change in say $y^{*}$ may not switch anybody's vote or preference. The following results should therefore be interpreted for economies in which the distance between any two neighboring income levels is very small relative to the magnitude of the shock. 
Proposition 3 Consider at the beginning of period 2 a small negative (positive) shock $\lambda<$ $1(\lambda>1)$. Assume that the p.d.f. of private incomes is constant up to some level $\overline{\bar{y}}>y^{* *}$.

a) If the shock affects private income, extra income and cost of candidacy ( $y, m$ and $c$ ) it reduces (increases) the number of people who support the corporation compared to period 1 if either $y_{1}^{*}>\underline{y}_{1}$ or $y_{1}^{* *}<\bar{y}_{1}$;

b) If the shock affects only private income and cost of candidacy, but not extra income, it increases (decreases) the number of people who support the corporation compared to period 1 if either $y_{1}^{*}>\underline{y}_{1}$ or $y_{1}^{* *}<\bar{y}_{1}$;

Proof: a) The critical private income values in period 2 are

$$
\begin{aligned}
y_{2}^{*} & =\lambda\left[Y_{1}-2 \sqrt{Y_{1}\left(Y_{1}+m_{1}\right)\left(1-s\left(\lambda m_{1}\right)^{-1}\right)}\right] \\
y_{2}^{* *} & =\lambda\left[Y_{1}+2 \sqrt{Y_{1}\left(Y_{1}+m_{1}\right)\left(1-s\left(\lambda m_{1}\right)^{-1}\right)}\right]
\end{aligned}
$$

Since all incomes are affected by the shock, more people at the lower end will support the firm if $F_{2}\left(y_{2}^{*}\right)<F_{1}\left(y_{1}^{*}\right)$, where $F_{t}$ is the cumulative density function over private incomes in period $t$. Note that these functions typically differ across periods because a proportional shock affects the location and size of the domain. When p.d.f. of private incomes is constant in the relevant range, support increases at the lower end if

$$
\frac{y_{2}^{*}-\lambda \underline{y}_{1}}{\lambda\left(\bar{y}_{1}-\underline{y}_{1}\right)}<\frac{y_{1}^{*}-\underline{y}_{1}}{\bar{y}_{1}-\underline{y}_{1}}
$$

This is equivalent to $\frac{y_{2}^{*}}{\lambda}<y_{1}^{*}$, which after inserting for the critical values and simplifying holds for $\lambda>1$. Hence the support for the corporation is reduced at the lower end of the income distribution when a negative shock occurs.

Similarly, a shock increases the support at the "upper end" if

$$
\frac{\lambda \bar{y}_{1}-y_{2}^{* *}}{\lambda\left(\bar{y}_{1}-\underline{y}_{1}\right)}<\frac{\bar{y}_{1}-y_{1}^{* *}}{\bar{y}_{1}-\underline{y}_{1}}
$$

which is equivalent to $y_{1}^{* *}<y_{2}^{* *} / \lambda$. This holds for a positive shock $\lambda>1$, but is reversed for negative shocks. 
b) The different shock structure affects the critical private income values $y^{*}$ and $y^{* *}$ in a different way. In fact, the shock now has the opposite effects. To see this, note that the lower critical value in period 2 now becomes

$$
y_{2}^{*}=\lambda\left[Y_{1}-2 \sqrt{Y_{1}\left(Y_{1}+m \lambda^{-1}\right)\left(1-s m^{-1}\right)}\right]
$$

and similarly for $y_{2}^{* *}$. Compared to (12), $y_{2}^{*} / \lambda$ is now increasing instead of decreasing in $\lambda$. Q.E.D.

Remark 2: The assumption that the p.d.f. is constant up to some upper threshold level allows me to make a comparison between the number of voters who have incomes less than lower critical values $y_{1}^{*}$ and $y_{2}^{*}$. The results could be overturned for different p.d.f. The reason for the upper threshold level $\overline{\bar{y}}<\bar{y}$ is that for a constant p.d.f. over the entire interval of incomes median income would equal mean income, an assumption that is usually contradicted empirically.

The intuition for part a) is as follows. Recall that for a given tax rate $\tau$, the net benefit of the corporation is $\left(1-\tau^{2}\right) m-s$. A negative shock that lowers extra income works in the direction of making the presence of the corporation less attractive. The region has to spend the same amount of resources to attract the corporation but the benefit decreases. At the margin this makes voters more inclined to use the tax system to redistribute income instead of attracting the corporation.

The opposite holds when the shock does not affect extra income. In this case the benefit and the cost of attracting the corporation stay the same, but the benefit increases relative to the gains from redistribution because the private income tax base has declined. This can be also seen by considering someone with below average income. The optimal tax rate in the presence of the firm $\tau=(Y-y) / 2(Y+m)$ now falls when a negative shock to private incomes only occurs. Thus a negative shock increases support for the corporation at the lower end of the income distribution.

The next result deals with the incentive of an opponent to become a candidate against a proponent of the firm. Regardless of the structure of shocks, a negative shock makes entry more attractive. 
Proposition 4 In period 1 a proponent of the firm is a candidate and an opponent of the firm is indifferent between entering and staying out of the race.

a) A negative shock in period 2 to all host variables leads the opponent to strictly prefer entry over no entry, holding the probability of winning constant. A positive shock has the opposite effect.

b) The result continues to hold if the shock does not affect the cost of candidacy, i.e. $c_{2}=c_{1}$, and the cost of candidacy is sufficiently small relative to the subsidy, i.e. $s>2 c_{1}$.

c) Suppose the proponent's income equals average income and the shock affects private incomes and cost of candidacy, but not extra incomes. In contrast to part a, a positive shock leads the opponent to strictly prefer entry over no entry, holding the probability of winning constant.

Proof: a) Consider two candidates: the first has income $y_{1}^{p} \in\left[y_{1}^{*}, y_{1}^{* *}\right]$ and is a proponent of the firm in period 1, and the second has income $y_{1}^{o}<y_{1}^{*}$ and is an opponent to the firm. In period 1 the opponent is indifferent between becoming a candidate and not becoming a candidate. This must imply that the two candidates win with probability one half. Therefore, for the opponent

$$
0.5\left[\left(1-\tau_{1}^{o}\right) y_{1}^{o}+g_{1}^{o}\right]+0.5\left[\left(1-\tau_{1}^{p}\right)\left(y_{1}^{o}+m_{1}\right)+g_{1}^{p}\right]-c_{1}=\left(1-\tau_{1}^{p}\right)\left(y_{1}^{o}+m_{1}\right)+g_{1}^{p},
$$

where the left hand side is the expected utility when the person becomes a candidate and the right hand side reflects the utility when the person is not entering the political race. This condition is equivalent to

$$
\left[\left(1-\tau_{1}^{o}\right) y_{1}^{o}+g_{1}^{o}\right]-2 c_{1}=\left(1-\tau_{1}^{p}\right)\left(y_{1}^{o}+m_{1}\right)+g_{1}^{p}
$$

A shock $\lambda$ that affects all host country variables and that is consistent with $y_{2}^{o}<y_{2}^{*}<y_{2}^{p}$ has the following effects on the preferred policies of the two candidates: The tax rates in period 2 are the same as in period 1 (by Proposition 1). The optimal lump sum subsidy of the opponent becomes $g_{2}^{o}=\lambda g_{1}^{o}$, while for the proponent it is $g_{2}^{p}=\lambda\left(g_{1}^{p}+s\right)-s$. The 
opponent's difference in expected utility from becoming a candidate and not becoming a candidate in period 2 is

$$
\frac{\lambda}{2}\left\{\left[\left(1-\tau_{1}^{o}\right) y_{1}^{o}+g_{1}^{o}\right]-\left[\left(1-\tau_{1}^{p}\right)\left(y_{1}^{o}+m_{1}\right)+g_{1}^{p}+s\left(1-\lambda^{-1}\right)\right]\right\}-c_{2}
$$

Using (15) to replace the first square bracket, we can simplify the condition to

$$
\lambda c_{1}-c_{2}+\frac{s}{2}(1-\lambda) .
$$

Expression (16) is positive under a negative shock if $c_{2}=\lambda c_{1}$ (i.e., the shock affects the cost of candidacy). Becoming a candidate is strictly preferred over not becoming a candidate if $\lambda<1$ and vice versa if $\lambda>1$. The expression is also positive under a negative shock if $c_{2}=c_{1}$ (i.e., the shock does not affect the cost of candidacy) and $s>2 c_{1}$. This proves part b.

c) When $y_{1}^{P}=Y_{1}$ and extra income is unaffected, the algebra simplifies dramatically because $y_{2}^{P}=Y_{2}, \tau_{1}^{P}=\tau_{2}^{P}=0$, and $g_{1}^{P}=g_{2}^{P}=-s$. Using (15) in the same way as above, the difference in expected utitity from entry and no entry equals

$$
\frac{\left(m_{1}-s\right)(\lambda-1)}{2}+\lambda c_{1}-c_{2}
$$

This is positive under a positive shock regardless how candidacy costs are affected (recall that $m_{1}>s$ is necessary for anybody to support the firm). Q.E.D.

When the shock affects all host variables, the opponent's cost of staying out of the race increase because the proponent still wants to attract the firm, but the subsidy is unchanged. This result could be overturned if the shock does not affect the cost of candidacy and the latter are big enough relative to the per capita subsidy. By contrast, shocks can work in the opposite direction if not all host variables are affected. In particular, if the proponent's income equals average income, her most preferred policy and hence the net benefit from attracting the corporation is the same in both periods. Yet, the positive shock increases the opponent's benefit from entering the race because the redistributional gains are higher due to a larger tax base.

The final result in this section deals with the opponent's chances of winning the election if the set of candidates is held fixed. The probability of winning depends on how the position 
of the critical voter, who is indifferent between the two candidates, shifts as a result of the shock.

Proposition 5 Assume the p.d.f. of private incomes is constant up to some level $\bar{y}$ and the shock affects all host variables. A negative (positive) shock increases (decreases) an opponentto-the-firm's probability of winning against a proponent of the corporation, holding the set of candidates fixed.

Proof: Define $\widetilde{y}_{1}$ as the person who is indifferent between the proponent and the opponent to the firm in period 1 when $y_{1}^{o}<y_{1}^{*}<y_{1}^{p}$ and hence $\tau_{1}^{p}<\tau_{1}^{o}$. All individuals with income $y<\widetilde{y}_{1}$ prefer the opponent, while all above prefer the proponent. The private income level of the indifferent person is given by

$$
\widetilde{y}_{1}=\frac{m\left[1-\left(\tau_{1}^{o}\right)^{2}\right]+Y_{1}\left[\tau_{1}^{p}\left(1-\tau_{1}^{p}\right)-\tau_{1}^{o}\left(1-\tau_{1}^{o}\right)\right]-s}{\tau_{1}^{p}-\tau_{1}^{o}},
$$

and is between the two candidates' income. After the shock in period 2, the person who is indifferent has private income

$$
\widetilde{y}_{2}=\frac{\lambda m\left[1-\left(\tau_{1}^{o}\right)^{2}\right]+\lambda Y_{1}\left[\tau_{1}^{p}\left(1-\tau_{1}^{p}\right)-\tau_{1}^{o}\left(1-\tau_{1}^{o}\right)\right]-s}{\tau_{1}^{p}-\tau_{1}^{o}},
$$

since the preferred tax rate of the two candidates is unchanged when a shock affects all host variables. The opponent to the corporation has now more political support, and hence a higher probability of winning, if $F_{1}\left(\widetilde{y}_{1}\right)<F_{2}\left(\widetilde{y}_{2}\right)$. Under a uniform distribution of incomes up to some level $\overline{\bar{y}} \geq y^{p}$, the condition simplifies to

$$
\widetilde{y}_{1}<\frac{\widetilde{y}_{2}}{\lambda} \text {. }
$$

This is the case if $\lambda<1$ because $\tau_{1}^{p}-\tau_{1}^{o}<0$.

The same logic applies when $y_{1}^{o}>y_{1}^{*}>y_{1}^{p}$ and hence $\tau_{1}^{p}>\tau_{1}^{o}$. Support for the opponent increases if $\widetilde{y}_{1}>\widetilde{y}_{2} / \lambda$, which holds when $\lambda<1$. Q.E.D.

Under a negative shock both candidates adjust their preferred policy. In fact, tax rates are unchanged and only the lump sum transfer adjusts. Since the subsidy to the firm is unaffected, the adjustment of the lump sum transfer is less than proportional (to the shock) 
if the proponent is elected, while the adjustment is proportional when the opponent is in office. The person who is indifferent between the two candidates in period 1 now favors the opponent. A similar result cannot be established for the case when the shock does not affect extra income.

All results in this section are partial in the sense that some variable is held fixed: the identity of the policy maker, the probability of winning, or the set of candidates. A general characterization of the comparative statics is analytically difficult. While the results suggest that a shock can lead to a backlash, it is important to have proof that this indeed can happen. In section 5 I will provide examples in which in equilibrium a backlash occurs. Before this is done, I consider the case when extra income is proportional to private income.

\section{Extra Income Proportional to Private Income}

In the previous section it was assumed that the presence of the corporation generates the same absolute extra income for every individual. This was instructive in order to show that even then there is political conflict. It is important to check the robustness of the previous results by considering a nonuniform structure of extra incomes. An alternative that is easy to solve for is the case of proportional extra incomes,

$$
m_{t}^{i}=k y_{t}^{i}
$$

where $k>0$ is a parameter. I show that under (21) the thrust of the main results, though with some modifications, stays the same.

Individual income in period $t$ is $w_{t}^{i}=(1-\tau)(1+\delta k) y_{t}^{i}+g$ under public policy $\{\delta, \tau, g\}$. I proceed as in section 3 by characterizing most preferred policies, properties of political equilibria in any given period $t$, and the effects of shocks on political outcomes. For the proportional case it is useful to define another threshold level

$$
y_{t}^{* * *}=Y_{t}\left(2 \sqrt{s \bar{m}_{t}^{-1}}-1\right)
$$

where $\bar{m}_{t}=k Y_{t}$ is average extra income. The threshold income level $y_{t}^{* * *}$ is less than average income $Y_{t}$ if average extra income $\bar{m}_{t}$ is greater than the per capita subsidy to the firm $s$. It is shown in the appendix that when $\bar{y}_{t} \leq 2 \underline{y}_{t}$, the most preferred policy by an individual with income $y_{t}$ is

$$
\left\{\delta_{t}=1, \quad \tau_{t}=\frac{Y_{t}-u_{t}}{2 Y_{t}}, \quad g_{t}=\frac{\left(Y_{+}^{2}-y_{+}^{2}\right)(1+k)}{4 Y_{t}}-s\right\}
$$


if $y_{t} \geq y^{* * *}$, and thus the corporation is attracted, while the preferred policy is

$$
\left\{\delta_{t}=0, \quad \tau_{t}=\frac{Y_{t}-y_{t}}{2 Y_{t}}, \quad g_{t}=\frac{Y_{t}^{2}-y_{t}^{2}}{4 Y_{t}}\right\}
$$

otherwise. The corporation is not attracted.

The difference between the uniform and proportional case is that in the former no individual would want to subsidize the firm if average extra income, and hence everyone's extra income, is less than the per capita subsidy. By contrast, in the proportional case, rich individuals may want to attract the firm even if average extra income is less than the per capita subsidy. What matters to an individual is the person's extra income, not the average. ${ }^{6}$ Another difference is that the preferred tax rate structure is the same regardless of the value of $\delta$.

When it comes to political equilibria, the uniform and the porportional cases are quite similar: The median income person is elected policymaker if the cost of candidacy are sufficiently small. It is easy to see that the firm is not attracted if median income $y^{m}$ is less than $y^{* * *}$. The result parallels Proposition $2 \mathrm{a}$ in that the rejection of the firm is more likely, the more skewed is the distribution of private incomes because the threshold income level $y^{* * *}$ depends positively on average income.

Similar results are also obtained when shocks occur at the beginning of period 2. If shocks affect private and extra incomes, it follows from (22) that the insights from Proposition 3a are unchanged: A positive shock increases support while a negative shock lowers the number of people who are in favor of the corporation (i.e., $y_{2}^{* * *} / \lambda<y_{1}^{* * *}$ if $\lambda>1$ ). By contrast, when the shock affects only private income, the shock does not change the support for the corporation because $y_{2}^{* * *} / \lambda=y_{1}^{* * *}$ for all $\lambda$ (as can be seen from (22) again). This result differs from the uniform case.

Using the same logic as above, it can also be shown that the results from Propositions 4a,b and 5 hold under proportional extra income. Looking back over the proofs, it becomes clear that what matters is how the opponent or an indifferent voter evaluate entry decisions and different policies. The evaluation depends on own private and extra income and not on the distributional assumptions.

\footnotetext{
${ }^{6}$ Of course, average extra income matters indirectly through the government budget constraint.
} 


\section{The Model at Work}

The results so far suggest that a voter backlash is possible when a shock occurs. The previous results, however, do not provide a full equilibrium analysis because either the elected policymaker, the probability of winning or the set of candidates is held constant. The purpose of this section is to show by way of examples that backlashes indeed occur in equilibrium. I focus on the case where the shock affects all host variables and extra income is uniform. The first example illustrates the role of income inequality and the possibility of policy reversals if the identity of the policy maker is not affected between periods. Example 2 constructs a case in which the shock changes the set of candidates and leads to a voter backlash with positive probability. In both examples it is assumed that there is only one individual of each type.

\section{Example 1}

There are three individuals with the following incomes: $y_{t}^{1}=10, y_{t}^{2}=15$, and $y_{t}^{3}=34$. For this economy average income is $Y_{t}=19.667$, and the critical income values are $y_{t}^{*}=14.836$ and $y_{t}^{* *}=24.498$, assuming that $m_{t}=10$ and $s=9.9$. Individual 2 is the median and would pay the subsidy to the firm. If instead $y_{t}^{3}=40$, individual 2 would no longer support the firm since $y_{t}^{*}=16.428$. For sufficiently small campaign costs individual 2 is elected and therefore the support of the corporation depends on the skewness of the distribution of private incomes.

Assume now that $y_{1}^{1}=10, y_{1}^{2}=15, y_{1}^{3}=34$ in period 1 . In period 2 , the region experiences a shock $\lambda=0.99$. Individual 2 has an income of 14.85 in period 2. Nobody supports the firm, however, because $y_{2}^{*}=y_{2}^{* *}=Y_{2}=19.47$. This is a simple situation of voter backlash, in which the median voter makes the decision in both periods if campaign costs are sufficiently small.

\section{Example 2}

In this example the shock in period 2 changes the identity of the policy maker. The example is constructed in such a way that in period 1 the unique equilibrium has a proponent of the corporation winning the election. In period 2 the proponent and an opponent enter and win the election with probability one half. The shock switches the vote of one individual who in period 1 supports the proponent, but votes for the opponent in period 2 . 
There are four individuals with incomes $y_{1}^{1}=10, y_{1}^{2}=20, y_{1}^{3}=28$ and $y_{1}^{4}=222$ in period 1. Let $m_{1}=10$ and $s=9$. This gives an average income of $Y_{1}=70$, and critical income levels $y_{1}^{*}=22.671$ and $y_{1}^{* *}=117.33$. The following table characterizes the most prefererred policies of all individuals in period $1 .^{7}$

\begin{tabular}{|l|l|l|}
\hline$\delta_{1}^{1}=0$ & $\tau_{1}^{1}=0.429$ & $g_{1}^{1}=17.143$ \\
\hline$\delta_{1}^{2}=0$ & $\tau_{1}^{2}=0.357$ & $g_{1}^{2}=16.071$ \\
\hline$\delta_{1}^{3}=1$ & $\tau_{1}^{3}=0.263$ & $g_{1}^{3}=6.488$ \\
\hline$\delta_{1}^{4}=1$ & $\tau_{1}^{4}=-0.152$ & $g_{1}^{4}=-23.048$ \\
\hline
\end{tabular}

Table 1 - Most Preferred Policies in Period 1

We can now find parameters under which only individual 3 becomes a candidate and wins the election in period 1. Table 2 provides information on utility levels (columns represent utility of a particular person, while rows represent the most preferred policy of a particular individual). If person 3 is the only candidate, entry is optimal for her if $c_{1} \leq 6.513$. If person 2 enters as well, each candidate gets two votes and thus wins with probability one half. Entry of person 2 is optimal only if costs are sufficiently low, i.e. $c_{1} \leq 0.158$ (= half the difference between 28.928 and 28.612). Person 2 does not enter if $c_{1}$ is larger than this.

\begin{tabular}{|l|l|l|l|l|}
\hline & $u_{1}^{1}$ & $u_{1}^{2}$ & $u_{1}^{3}$ & $u_{1}^{4}$ \\
\hline Policy of 1 & 22.862 & 28.571 & 33.142 & 144 \\
\hline Policy of 2 & 22.5 & 28.928 & 34.071 & 158.786 \\
\hline Policy of 3 & 21.238 & 28.612 & 34.513 & 177.588 \\
\hline Policy of 4 & 0 & 11.524 & 20.743 & 244.3 \\
\hline
\end{tabular}

\section{Table 2: Utilities in Period 1}

We also need to rule out entry of person 1 . Suppose person 1 enters against person 3. Person 2, however, prefers the policy of person $3(28.612>28.571)$ and hence person 1 can never win. Finally, consider the possibility that only person 2 becomes a candidate. For this not to happen, we need that person 3 should find entry against 2 optimal which is the case when $c_{1} \leq 0.221$.

\footnotetext{
${ }^{7}$ Individual 4's most preferred policy seems to contradict Proposition 1 because $y_{1}^{4}>y^{* *}$ should result in $\delta_{1}^{4}=0$. The reason for the discrepancy is that the condition $\bar{y}_{1}<2 \underline{y}_{1}+Y_{1}$ is violated in this example and hence the constraint $w_{1}^{1} \geq 0$ is binding. Individual 4's optimal policy must therefore be derived taking the constraint into accout. It turns out that individual 4 slightly prefers the presence of the firm.
} 
Hence, if $0.158<c_{1} \leq 0.221$ the unique equilibrium is that person 3 wins the election and supports the firm.

Consider now a shock at the beginning of period $2, \lambda=0.98$. This results in $y_{2}^{1}=9.8, y_{2}^{2}=$ 19.6, $y_{2}^{3}=27.44$ and $y_{2}^{4}=217.56$ in period 2. Because $m_{2}=9.8$ and $s=9$, average income is $Y_{2}=68.6$, and critical income levels are $y_{2}^{*}=26.693$ and $y_{2}^{* *}=110.51$. Note that this leaves the most preferred $\delta^{\prime} s$ and $\tau^{\prime} s$ for individuals 1 to 3 unaffected, while the most preferred lump sum subsidy changes to $g_{2}^{1}=16.8, g_{2}^{2}=15.75, g_{2}^{3}=6.178$ and $g_{2}^{4}=-22.544 .^{8}$

The shock leads to a different political outcome in period 2. Table 3 gives utility levels in period 2 .

\begin{tabular}{|l|l|l|l|l|}
\hline & $u_{2}^{1}$ & $u_{2}^{2}$ & $u_{2}^{3}$ & $u_{2}^{4}$ \\
\hline Policy of 1 & 22.4 & 28 & 32.48 & 141.12 \\
\hline Policy of 2 & 22.05 & 28.35 & 33.39 & 155.61 \\
\hline Policy of 3 & 20.633 & 27.86 & 33.642 & 173.86 \\
\hline Policy of 4 & 0 & 11.272 & 20.289 & 238.96 \\
\hline
\end{tabular}

Table 3: Utilities in Period 2

If person 1 enters against person 3, person 2 votes now for person 1 instead of person 3 (28>27.86). Hence both candidates win with probability one half if entering. In addition, person 3 finds entry optimal in that situation if $c_{1} \leq 0.593$ and person 1 enters if $c_{1} \leq 0.902$.

We conclude that when person 3 is the sure winner in period 1 , the firm will be rejected with positive probability in period 2 .

\section{Evidence and Discussion}

In this section I discuss two types of evidence for the theory spelled out above. There is anecdotal evidence and there are empirical studies that indirectly shed light on the theory.

The experience of two multinational firms may illustrate the backlash idea. The automobile maker Ford selected in 1997 the Brazilian state of Rio Grande do Sul as location for a new production facility after being offered a several hundred million dollar incentive package. In 1999, a new state government decided to stop making payments to Ford because

\footnotetext{
${ }^{8} \mathrm{~A}$ different logic applies for individual 4 for the same reason as above. The most preferred tax rate is $\tau_{2}^{4}=-0.150$.
} 
"the money was needed for public services and wages at a time when the Brazilian economy was stumbling." 9 Ford decided to find another Brazilian state to build its plant.

The second example involves the U.S. energy company Enron who is the biggest foreign investor in India. In 1993 the state of Maharashtra under the leadership of the Congress Party invited Enron to build the biggest power plant in India. ${ }^{10}$ The deal allowed Enron to charge high electricity rates. The Congress Party is ousted in state elections in 1995 by the nationalist Hindu Party BJP which campaigned by arguing that the electricity rates are too high. The new government scrapped the partly built plant. Only after negotiations that lowered the electricity rates Enron is allowed in 1996 to continue with its project. Yet in 1999 the deal comes under fire in elections again. This time the Congress Party campaigns against the power plant. ${ }^{11}$

There exists no direct test of the voter backlash hypothesis although several studies have looked at the determinants of foreign direct investment in the context of political risk, while others have considered the role of income inequality for growth of the economy and the stability of government. There is also a literature on the relationship between policy uncertainty and investment.

The evidence on political risk as factor explaining the location of FDI is mixed. Political risk is itself a composite of factors of which one is sometimes, but not always, the degree of income inequality. Wheeler and Mody (1992) find that political risk is not significant in explaining the FDI of U.S. firms. Howell and Chaddick (1994) review three different approaches of predicting political risk and find that for the Business Environment Risk Intelligence model wealth inquality has a small negative impact in explaining political risk. Singh and Jun (1995) show that political risk is a significant determinant of FDI flows for countries that have historically attracted large amounts of FDI. Lehmann (1999) compares exporting and FDI as different modes of entry to foreign markets. He finds that policy risk

\footnotetext{
${ }^{9}$ The citation and the information about this case come from Joseph B. White "Ford Motor Cancels Plans for Plant in Brazilian State that Halted Subsidy," Wall Street Journal, Interactive Edition, April $29,1999$.

${ }^{10}$ See Jonathan Karp "Enron Facility again becomes Political Target in Indian Race," Wall Street Journal, September 8, 1999.

${ }^{11}$ Further examples of voter backlashes exists. For instance, Mercedes started building a new plant in Alabama in 1993 after being offered a huge subsidy package. In 1994 the newly elected governor, who is elected because of his anti-subsidy platform, renegotiates the package after Alabama is unable to pay the subsidies. See "O Governor, won't you buy me a Mercedes plant? A bidding war's bite," The New York Times, Sept. 1, 1996.
} 
has a negative effect on foreign investment by U.S. multinationals. The policy risk variable in this study is not directly based on income inequality however.

The role of income inequality has been examined in several studies. Persson and Tabellini (1994) show theoretically and in a cross-country analysis that income inequality has negative effects on economic growth. Muller (1988) discusses the relationship between income inequality and the stability of democratic regimes. He shows that for well established democracies income inequality is reduced, but new democratic regimes may have short duration if income inequality is large.

One emprirical study considers the nexus between policy uncertainty and investment. Servin (1997) uses a real option approach to show that small policy uncertainty can have large effects on the timing of irreversible investment and applies this logic to the performance of African countries.

\section{Conclusions}

This paper has developed a theory of voter backlash that explains the behavior of host governments toward outside investors as the result of an internal political conflict. Citizens disagree over the net benefits of the presence of a corporation because attracting or keeping the corporation typically involves forgone redistribution. Economic shocks change how citizens evaluate the trade-off between the benefits of having the corporation and forgone redistribution. A voter backlash can occur when shocks change the number of supporters of the corporation, the set of candidates in an election, and the probability of winning. While the paper uses foreign investment as a particularly relevant example for the theory developed, it is clear that the model can be seen as a theory of voter backlash more generally.

For convenience I assumed that the decision making across periods can be separated. There are no dynamic links over time, like investment irreversibilities or an incumbent advantage. This is not to say that these dynamic links are unimportant or unrealistic, but rather it allows me to abstract from those aspects that are fairly well understood and not central to the argument presented. Introducing an investment irreversibility or an incumbent advantage probably makes a policy reversal less likely. If it is costly for the corporation to move its production after a location decisions was made, the host region needs to pay a smaller subsidy in the second period. Similarly, if the policy maker in the first period has an 
incumbent advantage, for example due to lower cost of candidacy in period 2 , the incumbent is less likely to be ousted from office. In both cases, however, it appears that a voter backlash is still possible if the economic shock is sufficiently strong.

From a modeling perspective introducing dynamic links raises an additional problem. For instance, if the firm becomes partially immobile after it chose a host region, the firm may not enter the region in the first place. This would require a more thorough modeling of the firm's strategy and other outside options. In the present framework this was not necessary because the corporation would always realize the value of its outside option.

A perhaps simple way of introducing dynamics is to assume that the firm can be attracted in period 2 only if it was present in period 1. Some implications are straightforward. If the firm was present in period 1 , the decision problem in period 2 is then the same as described by Propositions 1 and 2. On the other hand, if the firm was not present in period 1, we are in a framework similar to Meltzer and Richard (1981). When making decisions in period 1, citizens anticipate these outcomes in period 2. In period 1, citizen $i$ maximizes $w_{1}^{i}+E\left(w_{2}^{i}\left(\delta_{1}\right)\right)$ by choosing $\left\{\tau_{1}, g_{1}, \delta_{1}\right\} .{ }^{12}$ Second period expected utility depends on whether $\delta_{1}=1$ or 0 . Most preferred policies can now be derived in a similar way as above. Extending the model in this direction is left for future research.

\footnotetext{
${ }^{12}$ For simplicity I assume that per-period utility is equal to net income.
} 


\section{Appendix}

\section{A. Proof of Proposition 1}

Consider first the case $m_{t} \geq s$. Because in any period, utility is increasing in net income, an individual's maximization problem when private income is $y_{t}^{i}$ is equivalent to maximizing $\left(1-\tau_{t}\right)\left(y_{t}^{i}+\delta_{t} m_{t}\right)+g_{t}$ by choosing the tax rate, the lump sum subsidy and the indicator variable subject to the government budget constraint (3) and the constraint $\left(1-\tau_{t}\right) \underline{y}_{t}+$ $\left.\delta_{t} m_{t}\right)+g_{t} \geq 0$. The latter constraint guarantees that the person with lowest private income has nonnegative income. If this condition holds, all other individuals will have nonnegative incomes too.

I solve the problem in two steps. Initially I ignore the second constraint and then I will check that the solution obeys the nonnegativy constraint. Solving the government budget constraint for the lump sum subsidy and inserting in the objective function reduces the problem to two choice variables, the tax rate and the indicator variable. Taking the derivative with respective to the tax rate gives

$$
\tau_{t}\left(y_{t}^{i}\right)=\frac{Y_{t}-y_{t}^{i}}{2\left(Y_{t}+\delta_{t} m_{t}\right)} .
$$

Note that the second derivative with respect to the tax rate is negative. Plugging (25) back into the objective function gives after rearranging

$$
w\left(y_{t}^{i}, \delta_{t}\right)=\frac{\left(Y_{t}+2 \delta_{t} m_{t}+y_{t}^{i}\right)^{2}}{4\left(Y_{t}+\delta_{t} m_{t}\right)}-\delta_{t} s .
$$

The optimal policy is found by comparing utilities levels for $\delta_{t}=1$ and $\delta_{t}=0$. After simplifying and rearranging terms the individual who is indifferent between having and not having the firm has income that solves

$$
y_{t}^{2}-2 y_{t} Y_{t}+Y_{t}\left[4\left(Y_{t}+m_{t}\right) s m_{t}^{-1}-3 Y_{t}-4 m_{t}\right]=0 .
$$

Using the quadratic formula and collecting terms, we find the two critical values $y_{t}^{*}$ and $y_{t}^{* *}$. $\delta_{t}=1$ is preferred if $y_{t}^{i} \in\left[y_{t}^{*}, y_{t}^{* *}\right]$. Note that these boundary values may lie outside the interval of actual private incomes. The optimal tax rate is then found from (25).

Consider next the nonnegativity constraint for the lowest income person. Net income of this person is nonnegative if under the optimal tax policy chosen by an individual $j$ with 
income $y_{t}^{j}$

$$
\left(Y_{t}+2 \delta_{t} m_{t}+y_{t}^{j}\right)\left(2 \underline{y}_{t}+2 \delta_{t} m_{t}+Y_{t}-y_{t}^{j}\right) \geq 4\left(Y_{t}+\delta_{t} m_{t}\right) \delta_{t} s .
$$

Person $j$ may choose $\delta_{t}=0$. In that case the second bracket on the left-hand side must be nonnegative. This is always the case when $\bar{y}_{t} \leq 2 \underline{y}_{t}+Y_{t}$. On the other hand, if the person chooses $\delta_{t}=1$ then net incomes are nonnegative if

$$
\left(Y_{t}+2 m_{t}+\bar{y}_{t}\right)\left(2 \underline{y}_{t}+2 m_{t}+Y_{t}-\bar{y}_{t}\right) \geq 4\left(Y_{t}+m_{t}\right) m_{t},
$$

because the LHS of (28) is decreasing in $y_{t}^{j}$ and the RHS is increasing in $s$. Rearranging and collecting terms we find that (28) is equivalent to

$$
\bar{y}_{t}^{2}-2 \underline{y}_{t} \bar{y}_{t} \leq 2 \underline{y}_{t}\left(Y_{t}+2 m_{t}\right)+Y_{t}^{2} .
$$

It is easy to see now that (29) always holds if $\bar{y}_{t} \leq 2 \underline{y}_{t}+Y_{t}$. When the highest income equals $2 \underline{y}_{t}+Y_{t}$, then the inequality holds, and so it does for any value $\bar{y}_{t}<2 \underline{y}_{t}+Y_{t}$ because the LHS of (29) is increasing in $\bar{y}_{t}$.

Consider next the case $m_{t}<s$. In this situation nobody wants to attract the firm. To see this, consider an individual with income $y_{t}$ whose most preferred tax rate is $\tau_{t}^{1}$ when the firm is present. The utility level (ignoring campaign costs) in this situation is

$$
w_{t}\left(y_{t} ; \delta_{t}=1\right)=\left(1-\tau_{t}^{1}\right)\left(y+\tau_{t}^{1} Y\right)+\left[1-\left(\tau_{t}^{1}\right)^{2}\right] m_{t}-s .
$$

The term $\left[1-\left(\tau_{t}^{1}\right)^{2}\right] m_{t}-s$ is negative under the assumption, and hence the maximized utility in the presence of the firm is never higher than in the absence of the firm because in the absence of the firm an individual can choose $\tau_{t}=\tau_{t}^{1}$ and her utility is $\left(1-\tau_{t}^{1}\right)\left(y+\tau_{t}^{1} Y\right)$ which is higher than (30). Q.E.D.

\section{B. Preferred Policies under Proportional Extra Income}

An individual with income $y_{t}^{i}$ solves the following problem

$$
\max (1-\tau)(1+k \delta) y_{t}^{i}+\tau(1-\tau)(1+k \delta) Y_{t}-\delta s
$$

by choosing $\tau$ and $\delta \in\{0,1\}$. The optimal value of $\tau$ is independent of $\delta$ and is found by differentiating with respect to the tax rate. Preferred tax rates are proportional to private 
income, that is, $\tau=\left(Y_{t}-y_{t}\right) / 2 Y_{t}$. Inserting this back into (31) gives indirect utility

$$
\begin{aligned}
& w_{t}^{i}\left(\delta_{t}=1\right)=\frac{\left(Y_{t}+y_{t}^{i}\right)^{2}(1+k)}{4 Y_{t}}-s \\
& w_{t}^{i}\left(\delta_{t}=0\right)=\frac{\left(Y_{t}+y_{t}^{i}\right)^{2}}{4 Y_{t}} .
\end{aligned}
$$

The income of the person who is indifferent between the two choices is found by equating the two expressions. This gives a quadratic equation in private income. Using the quadratic formula the two solutions are

$$
y_{a / b}=-Y_{t} \pm 2 Y_{t} \sqrt{s / \bar{m}_{t}}
$$

The negative root always leads to a negative expression, while the solution to the positive root is called

$$
y_{t}^{* * *}=Y_{t}\left(2 \sqrt{s / \bar{m}_{t}}-1\right)
$$

Net income has to be nonnegative. The conditions for this to hold can be derived in a similar way as for Proposition 1. Consider the person with lowest private income $\underline{y}_{t}$. The person's net income is falling in the private income of the decision maker. If the elected person chooses $\delta_{t}=0$, the condition $Y_{t}+2 \underline{y}_{t} \geq \bar{y}_{t}$ is sufficient for making net income nonnegative. If, on the other hand, the choice is $\delta_{t}=1$, net income of the lowest person is always nonnegative if $\bar{y}_{t} \leq 2 \underline{y}_{t}$. The latter constraint is the binding one. 


\section{References}

Besley, T. and S. Coate (1996): An Economic Model of Representative Democracy, Quarterly Journal of Economics 112, 85-114.

Besley, T. and S. Coate (1996): Sources of Inefficiency in a Representative Democracy: A Dynamic Analysis, American Economic Review 88, 139-156.

Bond, E. and L. Samuelson (1989): Bargaining with Commitment, Choice of Techniques, and Foreign Direct Investment, Journal of International Economics 26, 77-97.

Coate, S. and S. Morris (1999): Policy Persistence, American Economic Review 89, 1327-1336.

Doyle, C. and S. van Wijnbergen (1994): Taxation of Foreign Multinationals: A Sequential Bargaining Approach to Tax Holidays, International Tax and Public Finance 1, 211-225.

Grossman, G.M. and E. Helpman (1994): Protection for Sale, American Economic Review 84, 833-850.

Howell, L.D. and B. Chaddick (1994): Models of Political Risk for Foreign Investment and Trade, The Columbia Journal of World Business, Fall, 71-91.

Laban, R. and H. C. Wolf (1993): Large-Scale Privatization in Transition Economies, American Economic Review 83, 1199-1210.

Meltzer, A.H. and S.F. Richard (1981): A Rational Theory of the Size of Government, Journal of Political Economy 89, 914-927.

Muller, E.N. (1988): Democracy, Economic Development, and Income Inequality, American Sociological Review 53, 50-68.

Osborne, M.J. and A. Slivinski (1996): A Model of Political Competition with Citizen Candidates, Quarterly Journal of Economics 111, 65-96.

Perotti, R. (1993): Political Equilibrium, Income Distribution, and Growth, Review of Economic Studies 60, 755-776.

Persson, T. and G. Tabellini (1994): Is Inequality Harmful for Growth?, American 
Economic Review 84, 600-621.

Rodrik, D. (1991): Policy Uncertainty and Private Investment in Developing Countries, Journal of Development Economics 36, 229-242.

Rodrik, D. (1997): Has Globalization Gone Too Far? Institute for International Economics, Washington D.C.

Servin, L.(1997): Uncertainty, Instability and Irreversible Investment: Theory, Evidence, and Lessons for Africa, Policy Research Working Paper No. 1722, The World Bank, Washington, D.C.

Singh, H. and K.W. Jun (1995): Some New Evidence on Determinants of Foreign Direct Investment in Developing Countries, Policy Research Working Paper No. 1531, The World Bank, Washington, D.C.

Wheeler, D. and A. Mody (1992): International Investment Locations Decisions, The case of U.S. firms, Journal of International Economics 33, 57-76. 
$\tau \boldsymbol{A}$

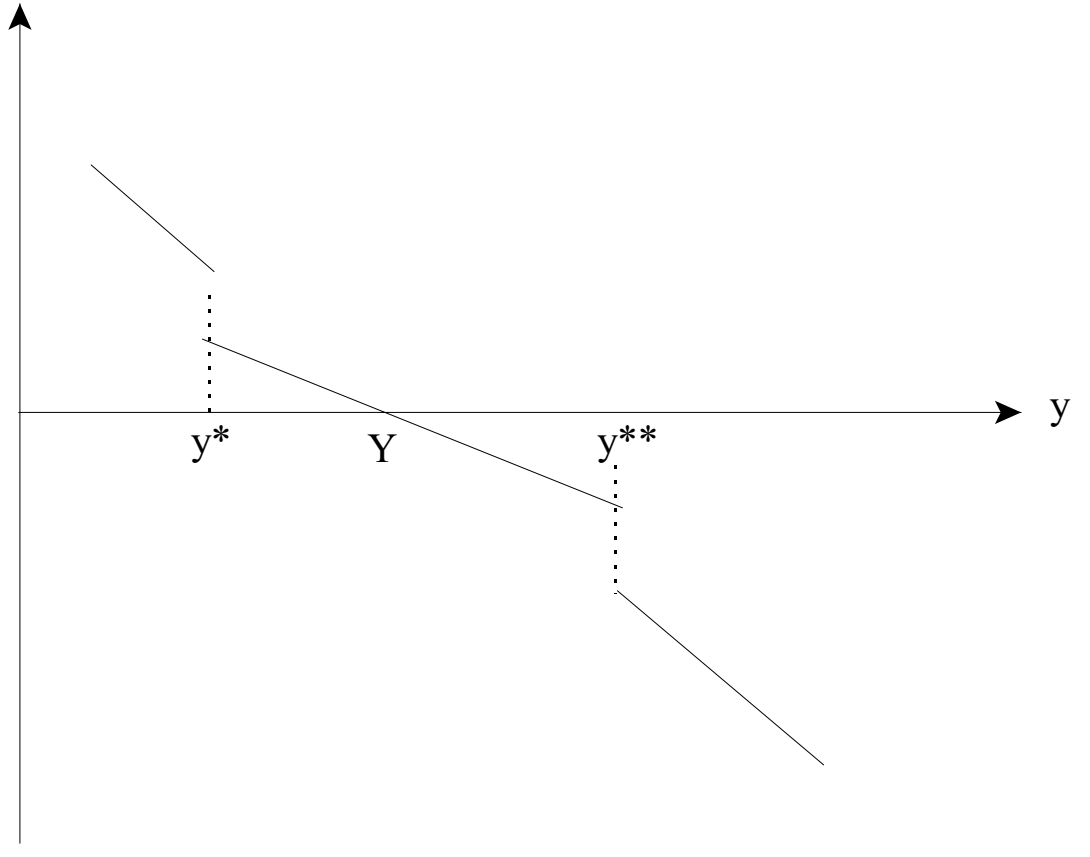


g A

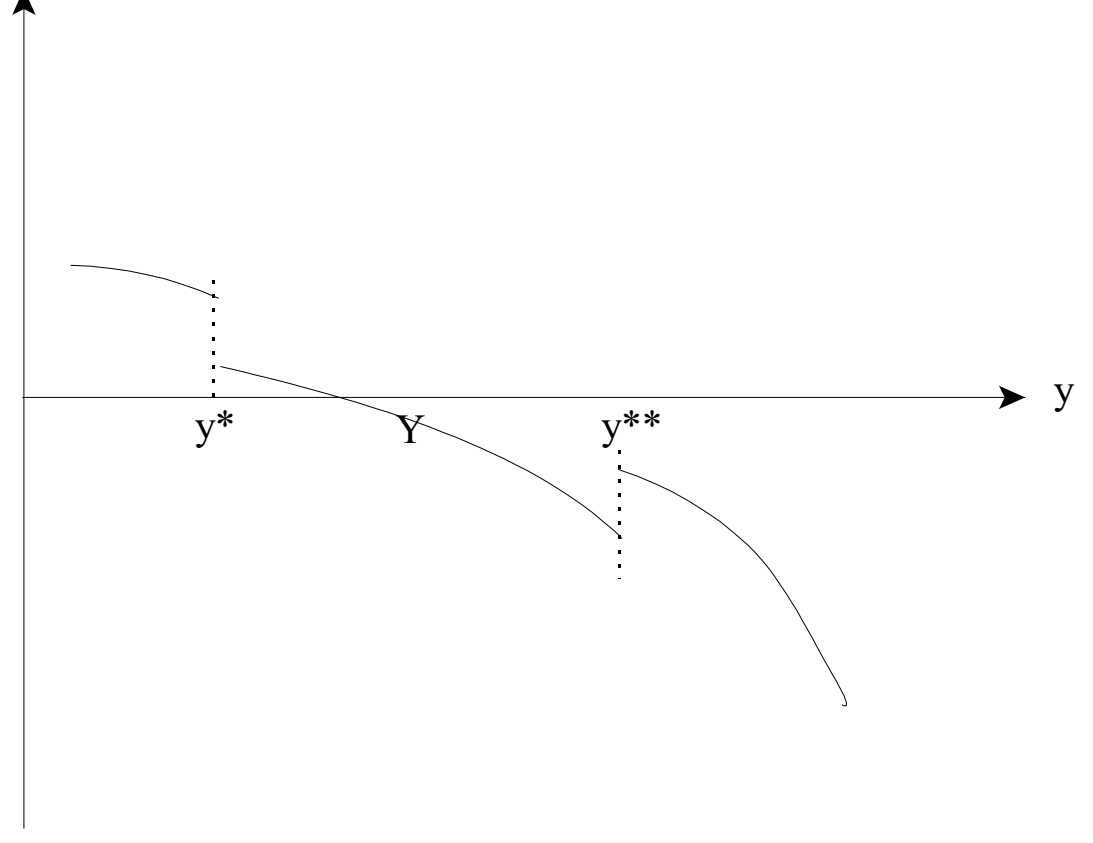




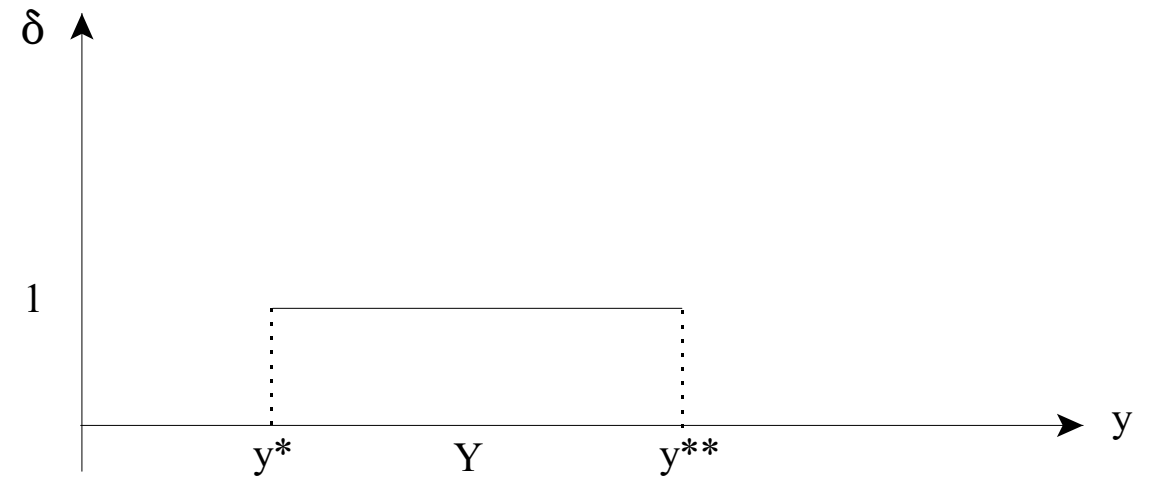

